\title{
CpG island methylation in Schistosoma- and non-Schistosoma-associated bladder cancer
}

\author{
Marina I Gutiérrez ${ }^{1}$, Abdul K Siraj ${ }^{1}$, Hussein Khaled ${ }^{2}$, Natalie Koon ${ }^{3}$, Wa'el El-Rifai ${ }^{3}$ and \\ Kishor Bhatia ${ }^{1,4}$ \\ ${ }^{1}$ King Faisal Specialist Hospital and Research Center, Riyadh, Saudi Arabia; ${ }^{2}$ National Cancer Institute, \\ Cairo, Egypt; ${ }^{3}$ Department of Medicine, University of Virginia Health Science Center, Charlottesville, VA, \\ USA and ${ }^{4}$ International Network for Cancer Treatment and Research, Brussels, Belgium
}

\begin{abstract}
Urothelial carcinomas (TCC) constitute the vast majority of bladder cancers in most of the world. On the other hand, squamous cell bladder carcinoma, a rare subtype in the Western world, is a common subtype in areas with endemic Schistosoma infection. Although schistosomal infection has been reported to influence DNA methylation, the pattern and extent of $\mathrm{CpG}$ island hypermethylation in squamous cell carcinomas remain unknown. In this study, we used methylation-specific PCR to characterize 12 cancer-related genes in 41 bladder cancer samples from Egypt (31 squamous cell carcinomas (SCC), 21 of them associated with Schistosoma and 10 TCC, five of which were Schistosoma-associated). The genes analyzed included E-cadherin, DAP-Kinase, $O^{6} M G M T, p 14, p 15, p 16, F H I T, A P C$, RASSF1A, GSTP1, RAR $\beta$ and $p 73$. Methylation of at least one gene was detected in all squamous cell tumors except two, and $45 \%$ of samples had at least three methylated genes. The average methylation index was $\mathbf{0 . 2 4}$, corresponding to three of the 12 analyzed genes. Schistosoma-associated tumors had more genes methylated than non-Schistosoma tumors (average MI: 0.29 vs 0.14$)(P=0.027)$. Although the extent of methylation in TCC (average MI: 0.16) was lower than in squamous cell carcinomas (SCC), the overall profile of methylation was similar, with Schistosoma-associated cases having a higher methylation index. Our results suggest that schistosomal involvement associates with a greater degree of epigenetic changes in the bladder epithelium.
\end{abstract}

Modern Pathology (2004) 17, 1268-1274, advance online publication, 21 May 2004; doi:10.1038/modpathol.3800177

Keywords: squamous cell carcinoma; transitional cell carcinoma; epigenetics; concurrent hypermethylation; methylator phenotype; infection; bilharziasis

Schistosomiasis is prevalent in several geographic regions, including Egypt, sub-Saharan Africa and the Middle East. ${ }^{1,2}$ Epidemiological data support a positive correlation between schistosomal infection and the risk to develop specific malignancies such as liver and bladder carcinomas and other tumors of the genitourinary tract. ${ }^{3-5}$ Schistosoma-associated bladder cancers pose an enormous socioeconomic burden in these countries, representing the most common malignancy. For example, one-third of all cancers in Egypt are bladder cancers. ${ }^{6}$ In contrast, in the US and Europe, where schistosomal infection is uncommon, bladder cancer ranks as the fifth most frequent malignancy. In addition to differences in incidence, other clinical differences also exist. Bladder cancers from non-schistosomal populations

Correspondence: K Bhatia, PhD, KFSHRC, Po Box 3354, MBC\#9816, Riyadh 11211, Saudi Arabia.

E-mail: Kishor_Bhatia@kfshrc.edu.sa

Received 1 December 2003; revised and accepted 21 January 2004; published online 21 May 2004 are mostly urothelial carcinomas (transitional cell carcinomas (TCC)), whereas those from schistosomal areas include a significant fraction of squamous cell carcinomas (SCC). ${ }^{7}$ There is a pronounced male preponderance with a peak incidence at 50 years of age, ${ }^{2}$ considerably lower than the median age at diagnosis in Euro-American population.

The mechanisms whereby urinary Schistosomasis induces bladder cancer are incompletely understood. Both chemical and physical carcinogenic pathways have been implicated and it has been suggested that chronic mechanical irritation by calcified eggs deposited in the bladder epithelium invokes changes in the urinary tract epithelia. ${ }^{8}$ Elevated levels of carcinogenic compounds, such as the $N$-nitroso compounds have also been hypothesized to influence the transformation of the uroepithelium. ${ }^{9}$

Over the past few years, information about the molecular pathogenesis of sporadic bladder cancers has begun to emerge, including extensive cytogenetic and molecular genetic analysis. ${ }^{10-13}$ Some 
comparative studies on Schistosoma- and nonSchistosoma-associated bladder cancers have also suggested different pathogenetic mechanisms. Primarily, differences in deletions and amplifications at specific loci between Schistosoma- and nonSchistosoma associated carcinomas suggest that loss at $3 p$ and $5 q$ are more frequent in former group. Previous data have also implicated deletions at $9 p$ to be frequent in some bladder carcinomas. Differences in gene expression and p53 mutations appear to exist between endemic and sporadic forms. ${ }^{14-19}$

The normal epigenetic equilibrium is dramatically altered in tumor cells where global hypomethylation of the genome occurs simultaneously with hypermethylation of $\mathrm{CpG}$ islands affecting critical genes such as tumor suppressor genes. ${ }^{20,21}$ Silencing of several tumor suppressor genes by promoter hypermethylation has been reported in non-schistosomal TCC of the bladder. ${ }^{22,23}$ It is not clear yet what causes these different patterns of methylation but it is likely that some selective growth advantages are gained during transformation. ${ }^{24,25}$

Several candidate genes that are silenced by methylation localize to regions that are often deleted in cancer. This observation raises the possibility of a deletion in one allele and inactivation of the other one by hypermethylation. At present, there is no information available on the extent, pattern and concurrency of methylation of these candidate genes in SCC.

There is growing evidence that genomic DNA of schistosomal-infected hosts undergoes promutagenic methylation damage. ${ }^{26}$ In this report, we have investigated our hypothesis that the presence of the parasite can influence the methylator phenotype of bladder cancers. We chose 12 cancer-related genes that have been previously assessed in TCC and that can have a potential in understanding etiological differences in the pathogenesis of Schistosoma- and non-Schistosoma bladder carcinomas. The results of this study can also contribute in identifying candidate genes useful for noninvasive assessment of endemic disease by urine testing in the future. ${ }^{27}$

\section{Materials and methods}

DNA from 41 bladder cancers from Egypt was available from previous studies ${ }^{14,18}$ including 31 SCC (21 Schistosoma- and 10 non-Schistosoma associated) and 10 TCCs (five associated to Schistosoma and five nonassociated). The diagnosis and classification were based on light microscopy examination using the WHO criteria. The SCC had squamous cell differentiation throughout the tumor. The following criteria were used for determining an association with Schistosoma: previous clinical history of bilharziasis, history of previous hematuria not related to the current malignancy, history of anti-schistosomal treatment, presence of schistosomal-related periportal fibrosis in hepatic ultrasound and histological verification of the presence of schistosomal cystitis in the bladder mucosa close to the tumor. To the best of our knowledge, none of the SCC that were placed in the non-Schistosomaassociated category had any association with Schistosoma infection based on our inclusion criteria. IRB approval was obtained for this study.

DNA was extracted from frozen tumor sections ${ }^{14,18}$ by the standard procedure of proteinase K digestion, phenol:chlorophorm extractions and alcohol precipitation. DNA was stored at $-20^{\circ} \mathrm{C}$. About $5 \mu \mathrm{g}$ of genomic DNA was bisulfite-treated and $100 \mathrm{ng}$ of this modified DNA was used as template in each methylation-specific PCR (MSP) as previously described. ${ }^{28}$

The 12 genes tested in this study were selected after careful review of the literature and included E-cadherin, DAP-Kinase, MGMT, p14, p15, p16, Fhit, APC, RASSF1A, GSTP1 and RAR $\beta .^{22,23,29-32} \mathrm{In}$ addition, we included $p 73$.

Table 1 shows the primers used, specific for the methylated (M) and the unmethylated (U) forms, and the PCR conditions. In the analysis of each candidate gene, four types of controls were included to ensure specificity: (1) in vitro methylated DNA, (2) nontreated DNA, (3) appropriate monoclonal cell lines with known methylation status and (4) nontemplate (blank). PCR products were analyzed by electrophoresis in $4 \%$ agarose gels stained with ethidium bromide.

\section{Statistical Analyses}

We defined a methylation index as the ratio between the number of methylated genes and the number of analyzed genes for each sample. Thus,

$$
\text { methylation index }=\frac{\text { total genes methylated }}{\text { total genes analyzed }} \text {. }
$$

Methylation status of all 12 genes was analyzed in 39 samples. In samples 8 and 12 (from Figure 2), methylation-specific PCR could be performed in nine and 10 genes, respectively. The average and median methylation indices in different histological subgroups were compared using Mann-Whitney $U$ tests. In order to analyze if there was an association of methylation between different loci we performed two-sided Fisher exact tests. Further coordination of methylation at the loci was analyzed by the MannWhitney $U$ test comparing the status of each gene (M or U) with a methylation index calculated with the remaining genes. The SPSS 11.0 package was used to perform all these statistical analyses.

\section{Results}

The 41 bladder cancer samples analyzed consisted of 31 SCC and 10 TCC. Methylation-specific PCRs were used to study the methylation status of 12 
Table 1 Primers and conditions of MSP analyses

\begin{tabular}{|c|c|c|c|c|}
\hline Gene & Primers & Annealing temp $\left({ }^{\circ} \mathrm{C}\right)$ & $\mathrm{MgCl}_{2}$ & Cycles \\
\hline E-cadherin M & $\begin{array}{l}\text { taattagcggtacggggggc } \\
\text { cgaaaacaaacgccgaatacg }\end{array}$ & 59 & 4.5 & 32 \\
\hline E-cadherin U & $\begin{array}{l}\text { ttagttaattagtggtatggggggtgg } \\
\text { accaaacaaaaacaaacaccaaataca }\end{array}$ & 59 & 4.5 & 32 \\
\hline DAP-kinase $\mathrm{M}$ & $\begin{array}{l}\text { ggatagtcggatcgagttaacgtc } \\
\text { ccctcccaaacgccga }\end{array}$ & 59 & 4.5 & 35 \\
\hline DAP-Kinase U & $\begin{array}{l}\text { ggaggatagttggattgagttaatgtt } \\
\text { caaatccctcccaaacaccaa }\end{array}$ & 59 & 4.5 & 35 \\
\hline$p 73 \mathrm{M}$ & $\begin{array}{l}\text { ggacgtagcgaaatcggggttc } \\
\text { accccgaacatcgacgtccg }\end{array}$ & 64 & 4.5 & 35 \\
\hline$p 73 \mathrm{U}$ & $\begin{array}{l}\text { aggggatgtagtgaaattggggttt } \\
\text { atcacaaccccaaacatcaacatcca }\end{array}$ & 60 & 4.5 & 35 \\
\hline$O^{6} M G M T \mathrm{M}$ & $\begin{array}{l}\text { tttcgacgttcgtaggttttcgc } \\
\text { gcactcttccgaaaacgaaacg }\end{array}$ & 56 & 3.5 & 35 \\
\hline$O^{6} M G M T \mathrm{U}$ & $\begin{array}{l}\text { tttgtgttttgatgtttgtaggtttttgt } \\
\text { aactccacactcttccaaaaacaaaaca }\end{array}$ & 57 & 4.5 & 35 \\
\hline$p 14 \mathrm{M}$ & $\begin{array}{l}\text { gtgttaaagggcggcgtagc } \\
\text { aaaaccctcactcgcgacga }\end{array}$ & 54 & 4.5 & 35 \\
\hline$p 14 \mathrm{U}$ & $\begin{array}{l}\text { ttttggtgttaaagggtggtgtagt } \\
\text { cacaaaaaccctcactcacaacaa }\end{array}$ & 56 & 4.5 & 35 \\
\hline$p 15 \mathrm{M}$ & $\begin{array}{l}\text { gcgttcgtattttgcggtt } \\
\text { cgtacaataaccgaacgaccga }\end{array}$ & 57 & 3.5 & 35 \\
\hline$p 15 \mathrm{U}$ & $\begin{array}{l}\text { tgtgatgtgtttgtattttgtggtt } \\
\text { ccatacaataaccaaacaaccaa }\end{array}$ & 59 & 4.5 & 35 \\
\hline$p 16 \mathrm{M}$ & $\begin{array}{l}\text { ttattagagggtggggcggatcgc } \\
\text { ccacctaaatcgacctccgaccg }\end{array}$ & 68 & 1.5 & 33 \\
\hline$p 16 \mathrm{U}$ & $\begin{array}{l}\text { ttattagagggtggggtggattgt } \\
\text { ccacctaaatcaacctccaacca }\end{array}$ & 58 & 4.5 & 33 \\
\hline FHIT M & $\begin{array}{l}\text { ttggggcgcgggtttgggtttttacgc } \\
\text { cgtaaacgacgccgaccccacta }\end{array}$ & $71-63$ & 1.5 & 32 \\
\hline FHIT U & $\begin{array}{l}\text { ttggggtgtgggtttgggtttttatg } \\
\text { cataaacaacaccaaccccacta }\end{array}$ & 64 & 1.5 & 33 \\
\hline$A P C \mathrm{M}$ & $\begin{array}{l}\text { tattgcggagtgcgggtc } \\
\text { tcaacgaactcccgacga }\end{array}$ & 62 & 3.5 & 35 \\
\hline$A P C \mathrm{U}$ & $\begin{array}{l}\text { gtgttttattgtggagtgtgggtt } \\
\text { ccaatcaacaaactcccaacaa }\end{array}$ & 62 & 1.5 & 35 \\
\hline$R A S S F 1 A \mathrm{M}$ & $\begin{array}{l}\text { ttcgtcgtttagtttggattttg } \\
\text { ccgattaaacccgtacttcg }\end{array}$ & 56 & 1.5 & 35 \\
\hline$R A S S F 1 A U$ & $\begin{array}{l}\text { tgttgtttagtttggattttgg } \\
\text { tacaacccttcccaacacac }\end{array}$ & 59 & 3.5 & 35 \\
\hline GSTP1 M & $\begin{array}{l}\text { ttcggggtgtagcggtcgtc } \\
\text { gccccaatactaaatcacgacg }\end{array}$ & $71-63$ & 1.5 & 37 \\
\hline GSTP1 U & $\begin{array}{l}\text { gatgtttggggtgtagtggttgtt } \\
\text { ccaccccaatactaaatcacaaca }\end{array}$ & $71-63$ & 1.5 & 37 \\
\hline$R A R \beta \mathrm{M}$ & $\begin{array}{l}\text { tcgagaacgcgagcgattcg } \\
\text { gaccaatccaaccgaaacga }\end{array}$ & 62 & 1.5 & 35 \\
\hline$R A R \beta \mathrm{U}$ & $\begin{array}{l}\text { ttgagaatgtgagtgaattga } \\
\text { aaccaatccaaccaaaacaa }\end{array}$ & 59 & 1.5 & 35 \\
\hline
\end{tabular}

candidate genes previously reported to be methylated in solid tumors. We observed that eight genes were frequently methylated in SCCs; DAP-Kinase (58\%), FHIT (40\%), RAR 3 (30\%), E-cadherin, APC, p16 (26\%), RASSF1A (26\%) and $O^{6} M G M T(23 \%)$. The remaining four genes were rarely methylated; p14 (13\%), p15 (10\%), p73 (7\%) and GSTP1 (3\%) (Figure 1).

Only two cases $(6 \%)$ did not show any methylation while $45 \%$ demonstrated at least three altered genes. To determine the extent of methylation in each sample, we calculated a methylation index that ranged from 0 to 0.83 with an average of 0.24 (median: 0.17) corresponding to three methylated genes.
In order to analyze the coexistence of methylation in different loci in SCC, we performed statistical analyses. Two-sided Fisher exact tests were used to compare the frequencies of each pair of genes. We identified an association between methylation in DAP-Kinase and in RASSF1A $(P=0.043)$. Methylation of $O^{6} M G M T$ was also associated with methylation of DAP-Kinase $(P=0.024)$, FHIT $(P=0.001)$ and $p 16 \quad(P=0.033)$. Further coordination of methylation at the 12 loci was analyzed by the Mann-Whitney $U$ test comparing the status of each gene ( $\mathrm{M}$ or $\mathrm{U}$ ) with a methylation index calculated with the remaining genes. Three genes, $O^{6} M G M T$, FHIT and APC were more likely to be methylated in samples with higher methylation index $(P=0.002,0.012$ and 0.029 , respectively). 


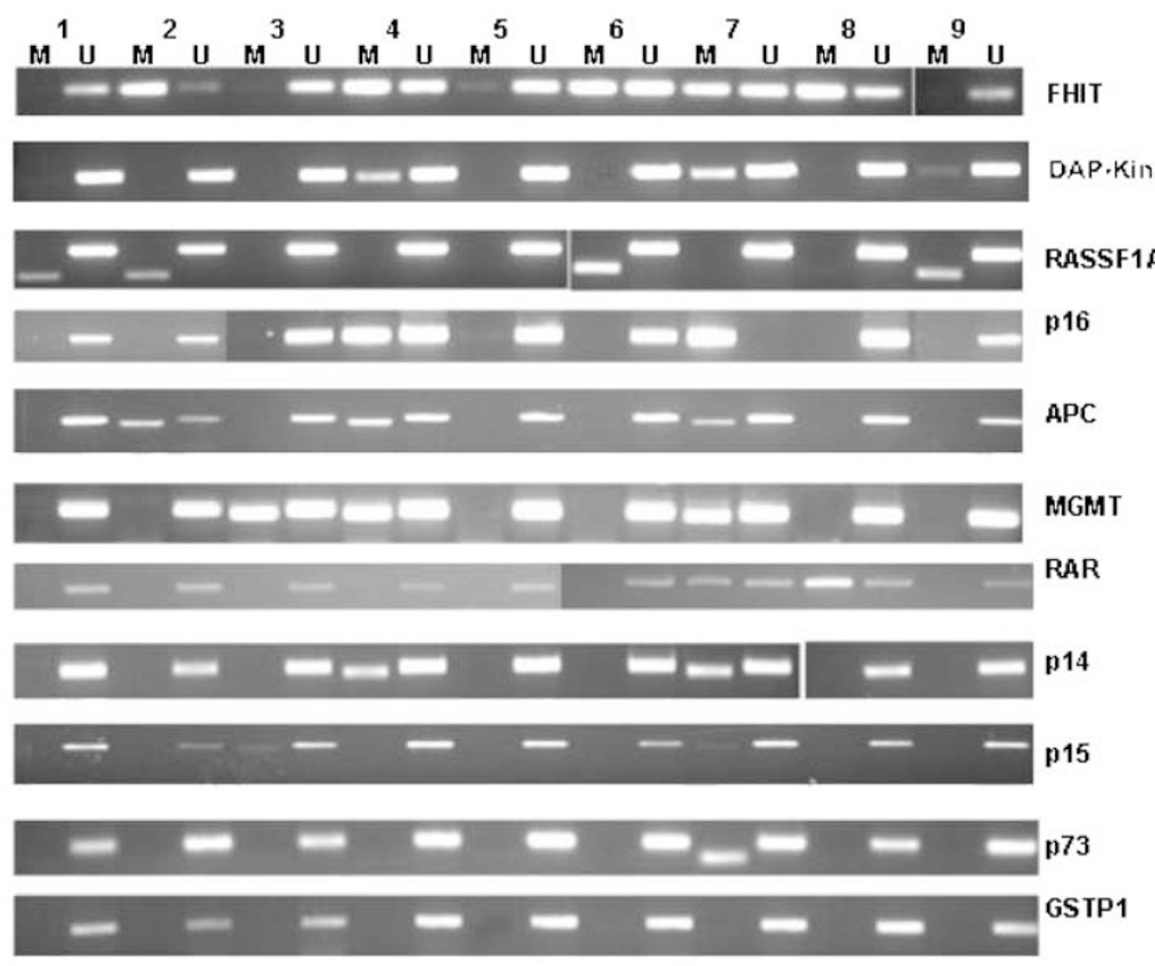

Figure 1 Methylation-specific PCR analyses of nine representative SCC samples (labeled 1-9 on the top). Each gene is indicated on the right. Both methylated (M) and unmethylated (U) reactions were amplified for each bisulfite-treated DNA and run in a $4 \%$ agarose gel.

We clustered the SCC based on the presence of Schistosoma. Tumors associated with the parasite demonstrated higher extent of methylation (median methylation index: 0.25, average methylation index: 0.29) than non-Schistosoma SCC (median methylation index: 0.08, average methylation index: 0.14) and this difference was statistically significant $(P=0.027)$. Furthermore, non-Schistosoma squamous carcinomas demonstrated a significantly lesser degree of methylation $(P=0.015)$ with the majority either not methylated or methylated at only one locus (Figure 2). The methylator phenotype also appears to be dissimilar. While methylation of $D A P$-Kinase and $R A R \beta$ were equally distributed between tumors with or without parasite, methylation of FHIT, RASSF1A, E-cadherin, p16, $A P C$ and $O^{6} M G M T$ tend to be more common in Schistosoma-associated SCC than in nonSchistosoma SCC.

In order to reconfirm the apparent influence of Schistosoma on epigenetic lesions, we analyzed the methylation status of the 12 genes in TCC cases from Egypt. Overall, this histological subtype had a lower extent of methylation (median methylation index: 0.17 , corresponding to two of 12 genes) than the SCC. Although the number of TCC samples in this study is small, we again observed a trend for higher methylation index in tumors associated with Schistosoma (median: 0.25) than in nonparasite tumors (median: 0.17).

\section{Discussion}

The development of cancer is associated with multiple genetic alterations such as mutations, deletions and amplification that deregulate the expression of several cancer genes. Nevertheless, the epigenetic mechanisms that contribute to gene deregulation, such as histone acetylation and hypermethylation, play an important role in gene silencing of several known genes such as those participating in different cellular processes like cell cycle (p16, p15), DNA repair (BRCA1, MLH1, $O^{6} M G M T$ ), apoptosis (DAP-Kinase, caspase 8) and drug-detoxification (GSTP1). ${ }^{20,21}$

Epigenetic changes are tumor-specific and therefore, not all the same genes are methylated in all tumor types. Several genes have been shown to be hypermethylated in bladder cancer, the most studied being $p 16, p 14$, E-cadherin, APC and RASS$F 1 A \cdot{ }^{22,23,29-33}$ These studies are based on TCC which is the prevalent histology (>90\%) in most of the world, including USA, Europe and China, and where bladder cancer ranks fifth. However, the highest frequency of bladder cancer worldwide is observed in Egypt with more than two-thirds of cases diagnosed as SCC. ${ }^{1-7}$ This high incidence is due to endemic infection by Schistosoma hematobium, which contributes to defining a characteristic pathology, that is Schistosoma-associated bladder cancer. 


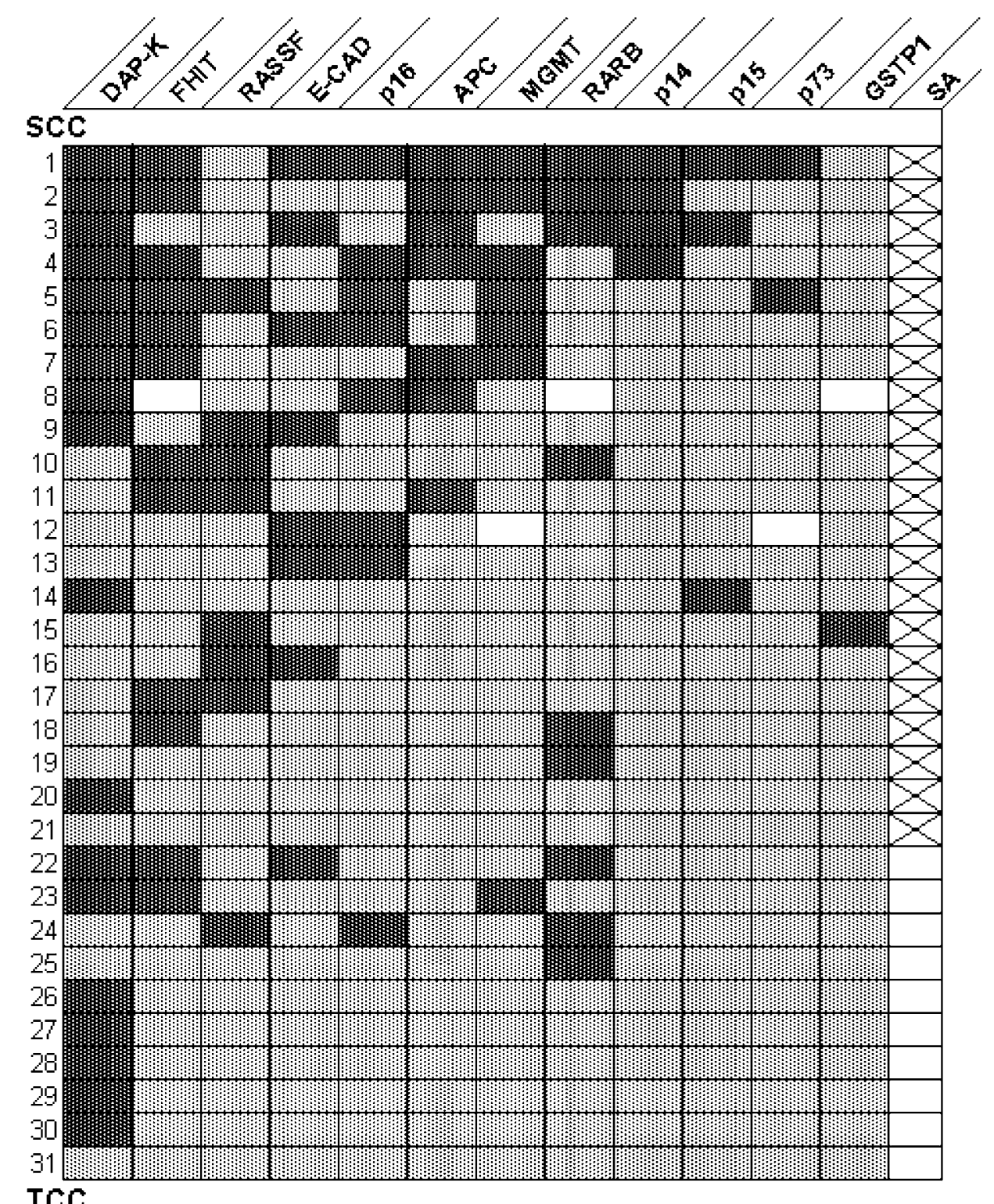

\section{$\mathrm{TCC}$}

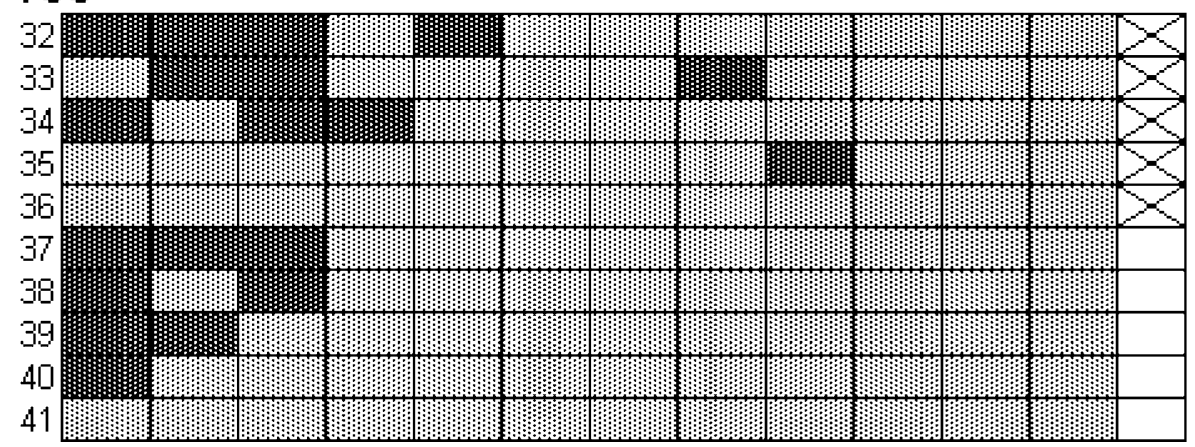

Figure 2 Concurrent methylation of 12 genes in bladder cancer. SCC are shown on the top panel and TCC are shown in the bottom panel. Dark gray squares depict methylation, light gray squares depict unmethylation and blank squares indicate no data available. The presence of Schistosoma (SA) is also shown with a crossed square.

We report in this study the pattern and degree of aberrant methylation of multiple genes in primary bladder cancer from Egypt. We included samples from 31 SCC (21 were Schistosoma-associated) and
10 TCC (five of them Schistosoma-associated). In all, 12 candidate genes were chosen based on previous reports of methylation in solid tumors. ${ }^{34}$ These included RASSF1A, FHIT, E-cadherin, DAP-Kinase, 
$A P C, R A R \beta, p 73, p 16, p 15, p 14, O^{6} M G M T$ and GSTP1. The data presented here demonstrates that multiple epigenetic lesions are frequent events in SCC. A total of $94 \%$ of samples carried at least one methylated locus and almost half carried three or more altered loci.

We compared our data in SCC with the available data from other bladder cancers, specifically TCC from USA and China. ${ }^{22,23}$ The observed frequency of methylation of DAP-Kinase, p16, p15 and GSTP1 were similar to those reported by Chan et al (2002). ${ }^{23}$ However, we observed a lower frequency of methylation of RAR $\beta$ and E-cadherin as well as a higher frequency of $O^{6} M G M T$ than in the Chinese patients with TCC of the bladder. Similarly, we noted some differences (in DAP-Kinase, FHIT, p16, $O^{6} M G M T$ and $R A R \beta$ ) and similarities (in RASSF1A, APC and GSTP1) with data from Maruyama et al. ${ }^{22}$ Therefore, some epigenetic lesions may be very specific for the urothelium, regardless of the histology (RASSF1A, $A P C$, GSTP1), but others may be cell-type dependent (FHIT and $O^{6} M G M T$ ).

It is highly likely that geographic variations in methylation patterns may explain some differences, especially because Egypt is an endemic area for Schistosomiasis. Indeed, methylation was associated with and influenced by the environment in hepatocellular carcinoma. ${ }^{35}$ Liver tumors from high-risk areas had higher levels of methylation than tumors arising spontaneously. Our data also support a role for environmental factors (eg Schistosoma) in the pathogenesis of hypermethylation in bladder cancer. Schistosoma-associated SCC demonstrated significantly higher extent of methylation (median methylation index: 0.25) than non-Schistosoma SCC (median methylation index: 0.08) $(P=0.027)$. To confirm that this is indeed caused by the parasite, we analyzed another histological type, that is, TCC and observed similar results (median methylation index 0.25 and 0.17, for Schistosoma-associated and non-Schistosoma TCC, respectively). The hypothesis that infective agents alter de novo hypermethylation has been proposed. Some examples are adenovirusinduced tumors, Epstein-Barr virus-infected cells and hepatitis B/C-associated liver cancer. ${ }^{35,36}$

It is interesting to note that TCC have about two times more chromosomal aberrations than SCC, ${ }^{17}$ while the opposite appears to be the case for epigenetic lesions. It is possible that genetic and epigenetic changes not only contribute to the malignant phenotype, but also that one compensates the other to achieve the threshold of events needed in the process of transformation.

Chan et $a l^{29}$ have reported frequent methylation of RASSF1A in TCC, especially in cases with loss of heterozygosity in $3 p 21$. In our limited data, we could not find such an association. Similarly, methylation of any of the cyclin-dependent kinase genes appeared to be independent of 9p21 deletion.

During statistical analyses of concomitant methylation in our cohort of samples, we determined that methylation of DAP-Kinase was significantly associated with methylation of RASSF1A $(P=0.043)$. Since both genes participate in apoptosis it is possible that they have a complementary effect in the suppression of cell death. In all, $74 \%$ of tumors had one of these gene inactivated. Other positive associations were found between methylation of $O^{6} M G M T$ and methylation of DAP-Kinase, FHIT, p16 and $A P C$, indicating that silencing of $O^{6} M G M T$ may be a late event in the pathogenetic process of urothelium transformation. Furthermore, three of these loci (FHIT, $A P C$ and $O^{6} M G M T$ ) were more likely to be methylated concurrently with other genes and therefore, they associated with a higher methylation index $(P<0.02)$.

The differences described between SCC and TCC of the bladder and between Schistosomaassociated cases and non-Schistosoma bladder tumors could reflect different etiologies and/or risk factors and may have relevant clinical implications. A larger study designed to provide correlations of the extent of methylation with clinicopathological characteristics such as age, sex, histological grade, stage, tumor recurrence, progression and survival should provide additional useful information. Environment-epigenetic interactions may be necessary to comprehend fully the complex process of carcinogenesis in the bladder epithelia.

\section{References}

1 Badawi AF, Mostafa MH, Probert A, et al. Role of schistosomiasis in human bladder cancer: evidence of association, aetiological factors, and basic mechanisms of carcinogenesis. Eur J Cancer Prev 1995;4:45-59.

2 Ibrahim S. Site distribution of cancer in Egypt: twelve years experience (1970-1981). In: Khogali M, Omar YT, Gjorgor A, Ismail AS, editors. Cancer Prevention in Developing Countries. Pergamon Press: Oxford, UK, 1986, pp. 20-32.

3 Johansson SL, Cohen SM. Epidemiology and etiology of bladder cancer. Semin Surg Oncol 1997;13:291-298.

4 Bedwani R, el-Khwsky $\mathrm{F}$, Renganathan $\mathrm{E}$, et al. Schistosomiasis and the risk of bladder cancer in Alexandria, Egypt. Br J Cancer 1998;77:1186-1189.

5 Matanoski GM, Elliott EA. Bladder cancer epidemiology. Epidemiol Rev 1981;3:203-229.

6 Khaled HM. Bladder cancer and Bilharziasis today. Cancer J 1993;6:65-71.

7 El-Bolkainy MN, Mokhtar NM, Ghoneim MA, et al. The impact of schistosomiasis on the pathology of bladder carcinoma. Cancer 1981;48:2643-2648.

8 Tricker AR, Mostafa MH, Spiegelhalder B, et al. Urinary nitrate, nitrite and $N$-nitroso compounds in bladder cancer patients with schistosomiasis (bilharzia). IARC Sci Publ 1991;105:178-181.

9 Ramchurren N, Cooper K, Summerhayes IC. Molecular events underlying schistosomiasis-related bladder cancer. Int J Cancer 1995;62:237-244.

10 Gonzalez-Zulueta M, Shibata A, Ohneseit PF, et al. High frequency of chromosome $9 p$ allelic loss and 
CDKN2 tumor suppressor gene alterations in squamous cell carcinoma of the bladder. J Natl Cancer Inst 1995;87:1383-1393.

11 Sandberg AA. Cytogenetics and molecular genetics of bladder cancer: a personal view. Am J Med Genet 2002;115:173-182.

12 Diggle CP, Cruickshank S, Olsburgh JD, et al. Identification of genes up-regulated in urothelial tumors: the 67-Kd laminin receptor and tumor associated tripsin inhibitor. Am J Pathol 2003;163:493-504.

13 Sanchez-Carbayo M, Socci ND, Lozano JJ, et al. Gene discovery in bladder cancer progression using cDNA microarray. Am J Pathol 2003;163:505-516.

14 Weintraub M, Khaled HM, Zekri A, et al. p53 mutations in Egyptian bladder cancer. Int J Oncol 1995;6:1269-1274.

15 Ghaleb AH, Pizzolo JG, Melamed MR. Aberrations of chromosomes 9 and 17 in bilharzial bladder cancer as detected by fluorescence in situ hybridization. Am J Clin Pathol 1996;106:234-241.

$16 \mathrm{Wu} \mathrm{RL}$, Osman I, Wu XR, et al. Uroplakin II gene is expressed in transitional cell carcinoma but not in bilharzial bladder squamous cell carcinoma: alternative pathways of bladder epithelial differentiation and tumor formation. Cancer Res 1998;58: 1291-1297.

17 Muscheck M, Abol-Enein H, Chew K, et al. Comparison of genetic changes in schistosome-related transitional and squamous bladder cancers using comparative genomic hybridization. Carcinogenesis 2000;21:1721-1726.

18 Rifai W, Kamel D, Larramendy ML, et al. DNA copy number changes in Schistsoma associated bladder cancer. Am J Pathol 2000;156:871-878.

19 Khaled HM, Aly MS, Magrath IT. Loss of Y chromosome in bilharzial bladder cancer. Cancer Genet Cytogenet 2000;117:32-36.

20 Costello JF, Fruhwald MC, Smiraglia DJ, et al. Aberrant CpG-island methylation has non-random and tumor-type-specific patterns. Nat Genet 2000;25: 132-138.

21 Esteller M, Herman JG. Cancer as an epigenetic disease: DNA methylation and chromatin alterations in human tumors. J Pathol 2002;196:1-7.

22 Maruyama R, Toyooka S, Toyooka KO, et al. Aberrant promoter methylation profile of bladder cancer and its relationship to clinicopathological features. Cancer Res 2001;61:8659-8663.
23 Chan MWY, Chan LW, Tang NLS, et al. Hypermethylation of multiple genes in tumor tissues and voided urine in urinary bladder cancer patients. Clinical Cancer Res 2002;8:464-470.

24 Esteller M. CpG island hypermethylation and tumor suppressor genes: a booming present, a brighter future. Oncogene 2002;21:5427-5440.

25 Issa J-P. Methylation and prognosis: of molecular clocks and hypermethylator phenotypes. Clin Cancer Res 2003;9:2879-2881.

26 Badawi AF, Cooper DP, Mostafa $\mathrm{MH}$, et al. Promutagenic methylation damage in liver DNA of mice infected with Schistosoma mansoni. Carcinogenesis 1993;14:653-657.

27 Esteller M. Relevance of DNA methylation in the management of cancer. Lancet Oncol 2003;4:351-358.

28 Gutiérrez MI, Siraj AK, Bhargava M, et al. Concurrent methylation of multiple genes in childhood ALL: correlation with phenotype and molecular subgroup. Leukemia 2003;17:1845-1850.

29 Chan MW, Chan LW, Tang NL, et al. Frequent hypermethylation of promoter region of RASSF1A in tumor tissues and voided urine of urinary bladder cancer patients. Int J Cancer 2003;104:611-616.

30 Ribeiro-Filho LA, Franks J, Sasaki M, et al. CpG hypermethylation of promoter region and inactivation of E-cadherin gene in human bladder cancer. Mol Carcinogenesis 2002;34:187-198.

31 Dominguez G, Carballido J, Silva J, et al. p14ARF promoter hypermethylation in plasma DNA as an indicator of disease recurrence in bladder cancer patients. Clin Cancer Res 2002;8:980-985.

32 Chang LL, Yeh WT, Yang SY, et al. Genetic alterations of p16INK4a and p14ARF genes in human bladder cancer. J Urol 2003;170:595-600.

33 Markl ID, Cheng J, Liang G, et al. Global and gene specific epigenetic patterns in human bladder cancer genomes are relatively stable in vivo and in vitro over time. Cancer Res 2001;61:5875-5884.

34 Esteller M, Corn PG, Baylin SB, et al. A gene hypermethylation profile of human cancer. Cancer Res 2001;61:3225-3229.

35 Shen L, Ahuja N, Shen Y, et al. DNA methylation and environmental exposures in human hepatocellular carcinoma. J Natl Cancer Inst 2002;94:755-761.

36 Ambinder RF, Robertson KD, Tao Q. DNA methylation and the Epstein-Barr virus. Semin Cancer Biol 1999;9:369-375. 